\title{
The Effects of Negative Pressure External High Frequency Oscillation on Cerebral Blood Flow and Cardiac Output of the Monkey
}

\author{
KEITH J. BARRINGTON, C. ANTHONY RYAN, ABRAHAM PELIOWSKI, MICHAEL, NOSKO, \\ AND NEIL N. FINER
}

Division of Newborn Medicine, Royal Alexandra Hospital and the Departments of Pediatrics and Neurosurgery, University of Alberta, Edmonton, Alberta, Canada

\begin{abstract}
The cerebral and systemic hemodynamic effects of negative pressure ventilation by external high frequency oscillation, utilizing a thoracoabdominal chamber, were investigated in six healthy adult monkeys. Cardiac output and cerebral blood flow were compared on external high frequency oscillation and conventional, positive pressure, mechanical ventilation in each animal. Cardiac output was measured by thermodilution and cerebral blood flow was measured by the intraarterial Xenon ${ }^{133}$ clearance technique. Oxygen delivery and consumption and systemic and pulmonary vascular resistances were calculated. There was no significant difference between the two ventilatory modes for any of these variables. Cardiac index on conventional mechanical ventilation was $2.87 \pm 0.391$. $\mathrm{min}^{-1} \cdot \mathrm{m}^{-2}$ (mean $\left.\pm \mathrm{SD}\right)$ and on external high frequency oscillation was $2.96 \pm 0.87 \mathrm{I} \cdot \mathrm{min}^{-1} \cdot \mathrm{m}^{-2}$. Cerebral blood flow was $43.9 \pm 9.1 \mathrm{ml} \cdot 100 \mathrm{~g}^{-1} \cdot \mathrm{min}^{-1}$ on conventional and $39.0 \pm 9.0 \mathrm{ml} \cdot 100 \mathrm{~g}^{-1} \cdot \mathrm{min}^{-1}$ on external high frequency ventilation. External high frequency oscillation is not associated with any adverse cardiovascular or cerebrovascular effects and could be introduced for short-term human trials. (Pediatr Res 21: 166-169, 1987)
\end{abstract}

\section{Abbreviations}

\section{CBF, cerebral blood flow}

CMV, conventional mechanical ventilation

EHFO, external high frequency oscillation

HFV, high frequency ventilation

Q, cardiac index

Despite the expanding literature describing the physiological and clinical effects of HFV by jet or oscillator in animal and clinical studies (1-4), no consistent advantages of HFV have been demonstrated when compared with $\operatorname{CMV}(5,6)$. In an effort to take advantage of the mechanisms of gas exchange during HFV, and noting the successful application of HFV to the chest wall of animals $(7,8)$, we have developed a method of EHFO applied to the abdomen and chest wall which, by use of negative pressure, maintains or improves lung volume (9). EHFO is effective both with and without an endotracheal tube, in cats with normal lungs and in cats with poorly compliant, saline

Reccived June 2, 1986; accepted September 25, 1986.

Address all correspondence and reprint requests to Dr. N. N. Finer, Division of Newborn Medicine, Royal Alexandra Hospital, Edmonton, Alberta, Canada, T5H 3 V9.

Supported by a grant from the Alberta Lung Association. K. J. B. is supported by the Alberta Heritage Foundation for Medical Research. lavaged, lungs (9). The avoidance of intubation is a particular advantage in a system with potential application to the neonate, as endotracheal tubes are associated with many morbid sequelae, including tracheal damage leading to subglottic stenosis, vocal cord paralysis, accidental bronchial intubation $(10,11)$, and the development of chronic lung disease (12).

The critically ill neonate may have an unstable cardiovascular system, being susceptible to frequent episodes of hypotension, and intra- and extracardiac shunts. Such infants are also at significant risk of intraventricular hemorrhages and periventricular leukomalacia, both thought to occur as a result of significant alterations in CBF (13).

Before proceeding to studies involving the human infant, we therefore considered it mandatory to ensure that our system of EHFO did not adversely affect cardiac function or CBF. In our previous study we were unable to obtain complete hemodynamic data. This study, therefore, was designed to compare the effect of CMV and EHFO on cardiac output at similar transpulmonary pressures, and global CBF at comparable levels of $\mathrm{PaCO}_{2}$, in healthy adult primates.

\section{METHODS AND PROCEDURES}

Six adult female cyomolgus monkeys (Macaca fascicularis, Charles River Research Corp., Port Washington NY) were sedated with ketamine hydrochloride $\left(10 \mathrm{mg} \cdot \mathrm{kg}^{-1}\right)$ intramuscularly. Anesthesia was induced with a loading dose of $50 \mu \mathrm{g} \cdot \mathrm{kg}^{-1}$ of fentanyl and maintained with an infusion at $1.5 \mu \mathrm{g} \cdot \mathrm{kg}^{-1} \mathrm{~h}^{-1}$. The monkey's weight and head to anus length were measured and the animal was orally intubated with a cuffed $5 \mathrm{~mm}$ internal diameter endotracheal tube.

The animals were conventionally ventilated during surgical preparation by a pressure limited, volume cycled, ventilator (model LS104-150, Bourns, Inc., Riverside, CA). Initial ventilatory rate was $30 \mathrm{bpm}$ and airway pressures of $8 / 2 \mathrm{~cm} \mathrm{H}_{2} \mathrm{O}$, measured at the proximal end of the tracheal tube by a Statham PM5 pressure transducer (Statham Instrument Co., Oxnard, CA).

Following intubation, muscle relaxation was maintained by Gallamine $\left(2 \mathrm{mg} \cdot \mathrm{kg}^{-1}\right.$ intravenously) every $45 \mathrm{~min}$. Body temperature was continuously monitored and maintained at $37.5 \pm$ $0.5^{\circ} \mathrm{C}$ by a heating pad and a radiant lamp warmer.

EHFO was provided, as previously described (9), by a thoracoabdominal chamber connected to a vacuum source and a high frequency piston pump capable of operating at frequencies from 1 to $50 \mathrm{~Hz}$ (Metrex Instruments Ltd., Brampton, Ontario, Canada). The chamber consisted of a Plexiglas cylinder $16.5 \mathrm{~cm}$ ID, $25 \mathrm{~cm}$ in length, and walls $0.6 \mathrm{~cm}$ thick, enclosing the animal from the axillae to lower abdomen. The edges of the chamber were lined with rubber, and a seal was achieved with plastic iris diaphragms at each end of the chamber. Mean chamber pressure 
was adjusted to the desired negative pressure using an external vacuum source, and chamber pressure oscillations occurred above and below this mean pressure. The amplitude of the chamber pressure swings (span) was controlled by adjusting the stroke volume of the oscillator. Chamber pressure was measured by a Statham pressure transducer (PM5) which had a flat frequency response to $40 \mathrm{~Hz}$. During EHFO a bias flow of 101 . $\mathrm{min}^{-1}$ of air and oxygen was provided connected by a Y connector to the endotracheal tube; the expired gases were vented to the atmosphere. The airway pressure was measured to ensure that the bias flow did not create positive pressure.

A specially adapted $5 \mathrm{Fr}$ sigmoid tipped rubber catheter was inserted into one femoral artery and advanced, under fluoroscopic control, to lie in the brachiocephalic trunk. The catheter position was confirmed by contrast angiography. A second catheter was inserted into the other femoral artery for continuous blood pressure recording (Statham P23db pressure transducer) and for obtaining blood for arterial blood gas analysis. A 5 Fr Swan-Ganz thermistor-tipped catheter (model 93-132-5F, American Edwards Laboratories, Santa Ana, CA) was inserted into a femoral vein and advanced under fluoroscopic control into the pulmonary artery. Pulmonary artery pressure, systemic arterial blood pressure, and heart rate were recorded continuously, and central venous pressure and pulmonary capillary wedge pressures were intermittently recorded on a Beckman 6 channel recorder.

Cardiac output was obtained by thermodilution (Edwards Cardiac Output Computer) after hand injection of $1 \mathrm{ml}$ of $5 \%$ dextrose in water at $0^{\circ} \mathrm{C}$; a method previously validated in vitro in this laboratory (14). Three cardiac output determinations were made, followed by a fourth if the initial readings differed by more than $10 \%$, and the mean value was recorded. Cardiac output determinations were performed at end-expiration on $\mathrm{CMV}$, and no attempt was made to inject at end-expiration during EHFO due to the rapidity of the oscillations.

Body surface area $\left(\mathrm{cm}^{2}\right)$ was calculated based on a formula for rhesus monkeys: weight ${ }^{0.6046}(\mathrm{~kg}) \times$ length $^{0.1862}(\mathrm{~cm}$; head to anus) $\times 514$. Q was calculated as cardiac output divided by surface area.

Arterial and mixed venous blood gases were analyzed by means of an IL Micro $13 \mathrm{pH} /$ blood Gas Analyser (Instrumentation Laboratories, Lexington, MA). Arterial and mixed venous oxygen saturation, oxygen content, and hemoglobin concentration were measured using an IL 282 cooximeter (Instrumentation Laboratories) fitted with a baboon coefficient.

To estimate CBF 2 to $3 \mathrm{mCi}$ of Xenon ${ }^{133}$ dissolved in $1 \mathrm{ml}$ sterile saline were injected by means of an automated injector into the brachiocephalic trunk followed by a saline flush over a 2- to 3-s period (15). Four lead collimated, gallium activated, NaI scintillation counters were arranged radially around the cranium of the monkey. Global CBF was calculated from the initial slope index of the decay curve. This method has been described in detail and standards for this laboratory previously established (16). In order to maintain a low background count of Xenon ${ }^{133}$ the effluent gases were vented to the atmosphere.

Following catheter insertions the animals were randomized to either CMV or EHFO according to a computer generated randomization code. Animals randomized to receive CMV first remained on the same ventilatory settings as previously stated, while EHFO was initially commenced at a rate of $3 \mathrm{~Hz}$ and pressures of $-8 /-2 \mathrm{~cm} \mathrm{H}_{2} \mathrm{O}$, which provided the best gas exchange in our previous study (9). Repeated arterial blood gases were taken and ventilatory adjustments made until $\mathrm{PaCO}_{2}$ was between 35 and 40 torr, $\mathrm{PaO}_{2}$ between 150 and 250 torr, and $\mathrm{pH}$ of 7.3 to 7.4. On CMV the ventilatory rate was the variable adjusted in order to control $\mathrm{PaCO}_{2}$; during EHFO the mean chamber pressure was maintained constant and the span was adjusted to control $\mathrm{PaCO}_{2} \cdot \mathrm{PaO}_{2}$ was maintained in the stated range in order to ensure that arterial blood remained fully saturated throughout all of the manipulations which were performed.
Once $\mathrm{PaCO}_{2}$ between 35 and 40 torr was obtained, $\mathrm{Q}$, oxygen consumption, systemic and pulmonary vascular resistances, and $\mathrm{CBF}$ were measured. The animal was then switched to the alternate form of ventilation and the procedure repeated, after attaining a $\mathrm{PaCO}_{2}$ in the same range. Cardiopulmonary and $\mathrm{CBF}$ measurements were repeated and the animal was returned to the original mode of ventilation. Several pairs of estimates of $\mathrm{CBF}$ and $Q$ were obtained in each animal, and the protocol continued until either three or four pairs of data were obtained depending on the time required to match $\mathrm{PaCO}_{2}$.

Because of the possible effects of mean transthoracic pressure on cardiac function, it was necessary to be able to correct $\mathrm{Q}$ for mean transthoracic pressure, which corresponds to mean airway pressure on CMV, and mean chamber pressure on EHFO. The piston pump used for EHFO produces a "sine wave" pressure waveform, therefore mean chamber pressure is simply calculated as the sum of peak negative (inspiratory) pressure and end expiratory pressure, divided by 2 . The ventilator used for $\mathrm{CMV}$, on the other hand, produces a variable pressure waveform, and the calibrated paper recording of the airway pressure was therefore subsequently digitized (Hewlett-Packard 9874A platen digitiser and HP 9845B microcomputer) and mean airway pressure was calculated using specially developed programs.

Statistical analysis consisted of paired and unpaired $t$ tests, for systemic, venous, and pulmonary pressures, vascular resistances, and $\mathrm{O}_{2}$ consumption. Cardiac output and $\mathrm{CBF}$ were compared between the two groups by an analysis of covariance, with mean transthoracic pressure and arterial $\mathrm{PCO}_{2}$, respectively, being used as the concomitant variables. The results were initially analyzed using the individual data points, this was done in order to maximize the chances of finding a significant adverse effect of EHFO if one existed. The results were also analyzed in terms of the mean result for each animal, using $n=6$. Data are presented as mean $\pm \mathrm{SD}$. $p$ value $<0.05$ was accepted as statistical significance.

\section{RESULTS}

The mean weight of the monkeys was $3.27 \mathrm{~kg}$ and their mean body surface area was $0.21 \mathrm{~m}^{2}$. Either three or four measurements of CBF and cardiopulmonary indices were obtained in each animal during CMV (total $=20$ ) and either two or three measurements during EHFO (total = 17). The unequal numbers in the groups represented an inability to match the $\mathrm{PaCO}_{2}$ on three occasions.

Blood pressure, pulmonary artery pressure, vascular resistances, and $\mathrm{O}_{2}$ consumption were unaffected by EHFO (Table 1). The EHFO group had slightly lower $\mathrm{PaCO}_{2}(p=\mathrm{NS})$ and significantly higher mean transthoracic pressure (6.5 versus 5.0 $\mathrm{cm} \mathrm{H}_{2} \mathrm{O}, p<0.0001$ ).

Cardiac output was not significantly affected by mode of ventilation and remained unchanged when corrected by covariance for the lower mean transthoracic pressure during EHFO. CBF was not significantly different between the two groups either uncorrected or corrected by covariance for the differences in $\mathrm{PaCO}_{2}$ between the groups. The results were not significant either when using individual data points or when using results averaged for each animal.

\section{DISCUSSION}

Periventricular leukomalacia and intraventricular hemorrhage are the two most common and disastrous causes of neurological morbidity in the preterm neonate. Both conditions are considered to occur as a result of alterations in $\mathrm{CBF}$, perhaps secondary to fluctuations in blood pressure beyond the autoregulatory limits of the neonatal cerebral circulation. It was therefore essential that major effects on the systemic and cerebral circulations were ruled out prior to clinical trials. In this study we have demonstrated that there are no significant alterations in cardiovascular 
Table 1. Comparison between CMV and EHFO on cardiopulmonary indices and CBF

\begin{tabular}{|c|c|c|c|c|c|}
\hline & \multirow[b]{2}{*}{$\mathrm{CMV}$} & \multirow[b]{2}{*}{ EHFO } & \multicolumn{3}{|c|}{$95 \%$ confidence limits } \\
\hline & & & $\mathrm{Xd}$ & of $\mathrm{Xd}$ & \\
\hline Mean transthoracic pressure $\left(\mathrm{cm} \mathrm{H}_{2} \mathrm{O}\right)$ & $5.0 \pm 1.2$ & $6.5 \pm 0.9 \dagger$ & -1.5 & -2.2 & -0.8 \\
\hline Mean arterial blood pressure $(\mathrm{mm} \mathrm{Hg})$ & $119 \pm 22.6$ & $113 \pm 21.3$ & +5.9 & -9.4 & +21.2 \\
\hline $\begin{array}{l}\text { Mean pulmonary artery pressure }(\mathrm{mm} \\
\mathrm{Hg})\end{array}$ & $19.2 \pm 7.9$ & $16.7 \pm 5.9$ & +2.5 & -2.3 & +7.3 \\
\hline $\begin{array}{l}\text { Mean pulmonary capillary wedge } \\
\text { pressure }(\mathrm{mm} \mathrm{Hg})\end{array}$ & $11.6 \pm 6.8$ & $7.9 \pm 6.4$ & +3.9 & -1.9 & +9.7 \\
\hline Cerebral venous pressure $(\mathrm{mm} \mathrm{Hg})$ & $8.8 \pm 5.0$ & $7.7 \pm 5.6$ & +1.5 & -2.1 & +5.2 \\
\hline $\mathrm{Q}\left(1 \mathrm{~min}^{-1} \mathrm{~m}^{-2}\right)$ & $2.87 \pm 0.39$ & $2.96 \pm 0.87$ & -0.1 & +0.7 & -0.5 \\
\hline$Q^{*}\left(1 \min ^{-1} \mathrm{~m}^{-2}\right)$ & $2.83 \pm 0.87$ & $3.03 \pm 0.39$ & -0.2 & +0.8 & -0.4 \\
\hline Stroke index $\left(\mathrm{ml} \mathrm{m}^{-2}\right)$ & $13.0 \pm 3.7$ & $12.7 \pm 3.8$ & 0.3 & +0.3 & -0.3 \\
\hline $\begin{array}{l}\text { Systemic vascular resistance }(\mathrm{mm} \mathrm{Hg} \\
\left.1^{-1} \operatorname{min~} \mathrm{m}^{2}\right)\end{array}$ & $43.7 \pm 11.4$ & $38.3 \pm 8.0$ & +5.4 & -1.7 & +12.4 \\
\hline $\begin{array}{l}\text { Pulmonary vascular resistance }(\mathrm{mm} \\
\left.\mathrm{Hg}^{-1} \min \mathrm{m}^{2}\right)\end{array}$ & $4.3 \pm 1.8$ & $4.9 \pm 1.8$ & +0.6 & -2.2 & +1.0 \\
\hline $\mathrm{O}_{2}$ consumption $\left(\mathrm{ml} \mathrm{min}^{-1} \mathrm{~m}^{-2}\right)$ & $148.3 \pm 55.6$ & $147.1 \pm 71.5$ & +1.2 & -45.4 & +47.8 \\
\hline $\mathrm{PaCO}_{2}$ (torr) & $36.7 \pm 2.3$ & $36.1 \pm 3.1$ & -1.9 & +1.6 & -5.4 \\
\hline $\mathrm{CBF}\left(\mathrm{ml} 100 \mathrm{~g}^{-1} \mathrm{~min}^{-1}\right)$ & $43.9 \pm 7.9$ & $39.0 \pm 10.1$ & +4.9 & -1.1 & +10.9 \\
\hline $\mathrm{CBF}\left(\mathrm{ml} 100 \mathrm{~g}^{-1} \mathrm{ml}^{-1}\right)$ & $43.6 \pm 9.1$ & $39.3 \pm 9.0$ & +4.3 & -1.7 & +10.3 \\
\hline
\end{tabular}

* Adjusted by covariance.

$+p<0.0001$.

$\mathrm{Xd}$, mean difference.

variables or $\mathrm{CBF}$ in adult primates when comparing $\mathrm{CMV}$ to EHFO. In addition, all the values of CBF obtained during these experiments were within the limits previously established by Petruk et al. (16) in this laboratory.

Nonhuman primates were studied for a number of reasons. First, there is an extensive experience with the present model in this laboratory, both in terms of cerebral hemodynamics (16) and estimation of cardiac output (14). Second, although we cannot be absolutely certain that newborn infants will respond in the same way, the cerebral circulation of the primate is similar to that of humans. Third, we have previously exclusively used cats in investigation of EHFO, and it was believed that an alternate species should be used in order to demonstrate that the efficacy of EHFO is not dependent on any peculiarity of that species.

The use of healthy animals in this study could be criticized. However, the induction of lung disease, by a method such as saline lung lavage, would have been certain to cause periods of hypoxia in the animal and would have caused profound changes in $\mathrm{CBF}$ and its control. In one animal, we performed five saline lung lavages following the completion of the above protocol. The resulting severe hypoxia was associated with low CBF followed by hyperperfusion in the recovery period. The use of healthy animals was therefore considered preferable to the confounding of our results with such uncontrollable variables. Neonatal animals were not available to us and, although the subjects of the current study were not at risk of developing intraventricular hemorrhage, no qualitative differences have been demonstrated in the physiology of the cerebral circulation in newborn as compared to adult mammals.

In the present study we neither ligated the external carotid artery nor reflected the temporalis muscle. Thus our measurements of "CBF" actually included flow in extracerebral tissues. However, this factor would have been the same on both modes of ventilation, and should not have interfered with our results. Furthermore, the prolongation of the experimental protocol, which would have been required for the surgical procedures, would have limited the time available for the remainder of the study.

While changes in global CBF are not a sensitive indicator of minor localized changes in cerebral perfusion (e.g. of the germinal matrix or periventricular watershed areas), we believe that the information which we have accumulated in this study was a necessary prerequisite to human studies. Our results agree with those of Toutant et al. (17) who, in the only previous study of CBF during HFV, found no difference in the global CBF of cats between CMV and HFV (100 breaths per minute).

Although we have previously reported on the efficacy of EHFO in nonintubated animals (9) the animals in the current study were intubated in order to alternate between CMV and EHFO. In addition, in order to perform repeat determinations of $\mathrm{CBF}$ by the Xenon ${ }^{133}$ technique it is essential that the background count of Xenon ${ }^{133}$ be maintained at low levels, thus requiring efficient evacuation of Xenon-rich expired gases.

High frequency ventilation is a form of mechanical vibration and many serious abnormalities have been reported to be induced by vibration. These include increases in respiratory rate, tidal ventilation, and oxygen consumption (18); increases in cardiac output, pulse pressure, and heart rate $(19,20)$; reductions in systemic vascular resistance (21); regional peripheral vasoconstriction (22); reduction in blood eosinophil count and increase in neutrophil count (23); histological renal and hepatic changes (24) and increase in blood SGOT concentration (24); chest and abdominal discomfort and pain (25); and death (26). Despite these reported adverse effects of vibration, HFV has been introduced for clinical practice without a full evaluation of its safety. This point has recently been emphasized by the description of hepatic abnormalities in neonatal baboons ventilated with internal oscillation (27).

Our concerns regarding the toxicity of vibration have led us to attempt to establish the probable safety of EHFO prior to instituting human investigation. In a controlled comparison of $\mathrm{CMV}$ and EHFO for $8 \mathrm{~h}$ in the cat, no difference was shown between the two modes of ventilation regarding changes in serum electrolyte and hepatic enzyme concentrations, and the gross and microscopic pathology of vital organs (28). We have now demonstrated that EHFO has no adverse cerebral or systemic hemodynamic effects.

Continuous negative pressures applied to the chest wall cause less impairment of cardiac output than equivalent pressures applied at the airway opening (29). We therefore anticipated that, if any effect of ventilatory mode was noted, EHFO would be associated with an increase in Q. Although we did not measure pleural and therefore transpulmonary pressures in our animals, $\mathrm{Q}$ was unaffected by ventilatory mode despite a higher transthoracic pressure on EHFO. Attenuation of the applied pressures 
probably occurred at the chest wall, and we suspect that the transpulmonary pressures on EHFO were less than the measured mean transthoracic pressures, and thus may have been comparable to those on CMV.

There was no apparent difference between the two ventilatory modes in terms of $\mathrm{CBF} / \mathrm{CO}_{2}$ response. However, a very narrow range of $\mathrm{PaCO}_{2}$ was examined in the current protocol, which may not have produced an adequate comparison.

Previous methods of applying negative pressure ventilation to newborn infants have largely been abandoned because of the difficulties in managing small infants in negative pressure ventilators. Our system differs from the older methods in that neck seals are not required and that temperature control is not a problem. We are developing a chamber for infant usage which has a rapid side opening for the removal of the subject with the minimum of delay.

In view of the results of this study, and our previous experience with EHFO, cautious short-term clinical trials of this method of ventilation in critically ill neonates appear to be warranted.

Acknowledgments. The authors thank Jo-Ann Kimball, R.N. for her excellent technical assistance and Dr. Sima Sconyers for her invaluable advice.

\section{REFERENCES}

1. Bohn DJ, Miyasaka K, Marchak BE, Thompson WK, Froese AB, Bryan AC 1980 Ventilation by high frequency oscillation. J Appl Physiol 48:710-716

2. Carlo WA, Chatburn RL. Martin RJ, Lough MD, Shivpuri CR. Anderson JV, Fanaroff AA 1984 Decrease in airway pressure during high-frequency jet ventilation in infants with respiratory distress syndrome. J Pediatr 104:101107

3. Marchak BE, Thompson WK. Duffty P, Miyaki T. Bryan MH. Bryan AC, Froese AB 1981 Treatment of RDS by high-frequency oscillatory ventilation: a preliminary report. J Pediatr 99:287-292

4. Rieke H. Hook C. Meyer M 1983 Pulmonary gas exchange during highfrequency ventilation in dogs. Respir Physiol 54:1-17

5. Carlon GC. Klain M 1984 International symposium on high frequency ventilation. Crit Care Med 12:703-704

6. Truog WE. Standaert TA, Murphy JH, Woodrum DE. Hodson WA 1984 Effects of prolonged high frequency oscillatory ventilation in premature primates with experimental hyaline membrane disease. Am Rev Respir Dis 130:76-80

7. Zidulka A, Gross D, Minami H, Vartian V. Chang HK 1983 Ventilation by high frequency chest wall compression in dogs with normal lungs. Am Rev Respir Dis 127:709-713

8. Harf A, Bertrand C. Chang HK 1984 Ventilation by high frequency oscillation of the thorax or trachea in rats. J Appl Physiol 56:155-160
9. Hayek Z, Peliowski A, Ryan CA, Jones RL, Finer NN 1986 External high frequency oscillation in cats: experience in the normal lung and after saline lung lavage. Am Rev Respir Dis 133:630-634

10. Joshi VV, Mandavia SG, Stern L, Wiglewsworth FW 1972 Acute lesions induced by endotracheal intubation. Occurrence in the upper respiratory tract of newborn infants with respiratory distress syndrome. Am J Dis Child 124:646-649

11. Hedley-White J, Burgess GE, Feeley TW, Muller MG 1976 Applied Physiology of Respiratory Care. Little Brown, Boston, pp 3-11

12. Stern L 1979 The etiology and pathogenesis of bronchopulmonary dysplasia. J Pediatr 95:867-869

13. Pape KE. Wigglesworth JS 1979 Haemorrhage, Ischaemia and the Perinatal Brain. Spastics International Medical Publishers, London

14. Norris SL. King EG, Grace M, Weir B 1986 Thermodilution cardiac outputan in vitro model of low flow states. Crit Care Med 14:57-59

15. Snyder RE, Overton TR, Boisvert DPJ, Petruk KC 1976 An automatic bolus injector for use in radiotracer studies of blood flow: design and evaluation. Br J Radiol 49:1033-1036

16. Petruk KC, Weir BK, Overton TR, Marriot MR, Grace MG 1974 The effect of graded hypocapnia and hypercapnia and cerebral vessel caliber in the rhesus monkey: study of cerebral hemodynamics following subarachnoid hemorrhage and traumatic internal carotid spasm. Stroke 5:230-246

17. Toutant SM, Todd SM, Shapiro H 1983 Cerebral blood flow during high frequency ventilation in cats. Crit Care Med 11:712-715

18. Hood WB. Higgins LS 1965 Circulatory and respiratory effects of whole body vibrations in anesthetized dogs. J Appl Physiol 20:1157-1162

19. Clark JG, Williams JD, Hood WB Jr, et al 1967 Initial cardiovascular response to low frequency whole body vibration in humans and animals. Aerospace Med 38:464-467

20. Hood WB, Murray RH, Urschel CW, Bowers JA, Clark JG 1966 Cardiopulmonary effects of whole-body vibration in man. J Appl Physiol 21:17251731

21. Liedtke JA, Schmid PG 1969 Effect of vibration on total vascular resistance in the forelimb of the dog. J Appl Physiol 26:95-100

22. Dieckman D 1958 Einfluss horizontaler mechanischer schwingungen auf den menschen. Int Z Angew Physiol 17:83-100

23. Cope FW. Polis BD 1957 Some effects of prolonged low frequency vibration on the molecular and cellular composition of blood. Report NADC-MA5715 United States Naval Air Development Center

24. Ivanovich E, Antov G, Kazakova B 1977 Enzymic and ultrastructural changes in rat liver due to whole body vibration. Int Arch Occup Environ Health 39:249-254

25. Magrid EB, Coerman RR, Ziegenrucker GH 1960 Human tolerance to whole body sinusoidal vibration. Aerospace Med 31:915-924

26. Aston R, Roberts VL 1965 The effects of drugs on vibration tolerance. Arch Int Pharmacodyn 155:289-299

27. Bell RE, Coalson JJ, Ackerman NB, Null DM, Kuehl TJ, Escobedo M, DeLemos RA 1986 A nonpulmonary complication of high-frequency oscillation. Crit Care Med 14:207-210

28. Ryan CA, Peliowski A, Perry A, Finer NN 1986 External high frequency oscillation (EHFO): histological and biochemical effects. Pediatr Res 20:439A (abstr)

29. Krumpe PE, Zidulka A, Urbanetti J, Anthonisen NR 1977 Comparison of the effects of continuous negative external chest pressure and positive endexpiratory pressure on cardiac index in dogs. Am Rev Respir Dis 115:39-45 